\title{
Post Fire Cracker Injury Corneal Perforation with Endophthalmitis in a Child
}

\author{
Bhagabat Nayak $^{1 *}$ and Lipika Nayak ${ }^{2}$ \\ ${ }^{1}$ All India Institute of Medical Sciences, India \\ ${ }^{2}$ Institute of Medical Sciences and SUM Hospital, India
}

Submission: July 09, 2018; Published: September 21, 2018

*Corresponding author: Bhagabat Nayak, AIIMS, Bhubaneswar, India, 751019, Tel: 7250076800; Email: bhagabat80@gmail.com

\section{Introduction}

An 8 years old male presented with rapidly detoriating vision in right eye with pain, redness and watering over a period of four days. He had history of trauma to right eye with fire cracker injury 3 days back on eve of festival "Diwali" in India. Right eye had visual acuity of perception of light (PL) only. On slit lamp examination, he had corneal perforation and hypopyon. Ultrasonography was suggestive of endophthalmitis. The exudates from vitreous and anterior chamber were sent for microbiological testing which showed the organism to be Bacillus cereus. He was treated with repair of corneal perforation with intracameral Vancomycin wash and intravtreal Vancomycin injection. Two days post operatively the hypopyon was cleared with decreased exudates in vitreous. Topical moxifloxacin was continued and second dose of intravitreal Vancomycin was given after 72 hours. After 7 days the symptoms improved with vision of $4 / 60$.

\section{Background}

"Diwali" is an Indian festival where people celebrate it with lights and different types of fire crackers. The injury due to firecracker is a common problem especially in children due to unawareness and certain minimum preventive measures not taken by them or their parents. Injury to eye is very grave condition, and prognosis depends on type of injury, severity of injury and time at presentation.

We are highlighting the fate of firecracker injury leading to serious infection in form endophthalmitis where we could save the vision to some extent in this patient due to prompt intervention and proper antibiotics.

\section{Case Presentation}

An 8 years old male presented with rapidly detoriating vision in right eye with pain, redness and watering over a period of four days. He had history of trauma to right eye with fire cracker injury 3 days back on eve of festival "Diwali" in India. On examination, right eye had visual acuity of perception of light (PL) only with accurate projection of light rays in all quadrants. His left eye was normal with visual acuity of 6/6. On slit lamp examination, the right eye had congestion and exudates in anterior chamber inferiorly, the hypopyon (Figure 1). On higher magnification with slit illumination, there was corneal perforation, yellowish membranous exudates in anterior chamber and hypopyon of height of $2.5 \mathrm{~mm}$ (Figure 2).
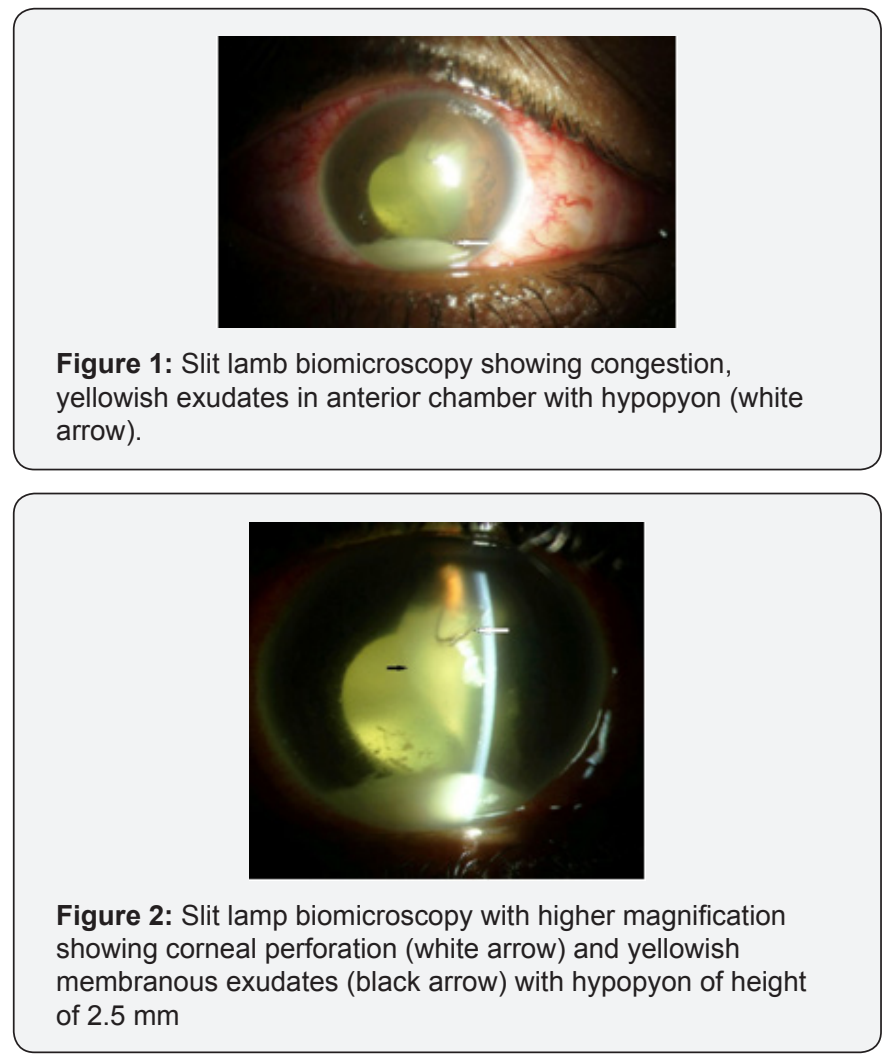

Investigations

Ultrasonography (USG) was done to rule out the posterior segment involvement which showed there was mild to moderate amplitude spikes, suggestive of exudates in vitreous cavity (Figure 3) confirming the diagnosis of endophthalmitis. There was no retained intra ocular foreign body. Microbiological testing of anterior chamber and vitreous aspirate was done to know the organism and its sensitivity to antibiotics which showed the organism to be Bacillus cereus. 


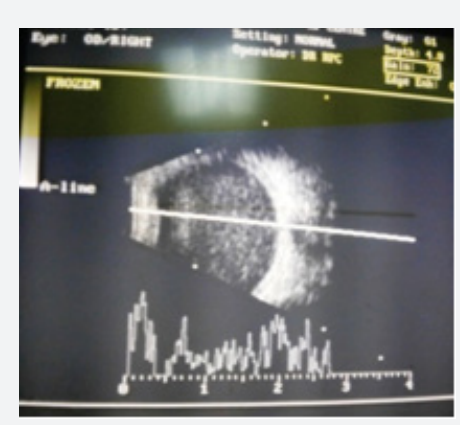

Figure 3: Ultrasonography image showing vitreous cavity full of mild to moderate spikes suggestive of endophthalmitis.

\section{Differential Diagnosis}

The diagnosis of post traumatic corneal perforation with endophthalmitis was straight forward with history of injury, slit lamp bio microscopic examination, USG findings and microbiological report.

\section{Treatment}

As there was corneal perforation, we repaired the corneal perforation with 10-0 monofilament nylon suture with anterior chamber wash. The exudates from vitreous and anterior chamber were sent for microbiological testing after vitreous aspirate was done with 23gauge needle. Intracameral Vancomycin washes with intravitreal Vancomycin $(1.15 \mathrm{mg}$ in $0.01 \mathrm{ml}$ ) injection and Ceftazidime $(2.25 \mathrm{mg}$ in $0.01 \mathrm{ml}$ ) was given thereafter. The microbiological testing of the sample showed the organism to be B. cereus. Two days post operatively the hypopyon was cleared with decrease of exudates in vitreous on repeat USG. Topical moxifloxacin 0.5\%, 6 times was continued and second dose of intravitreal Vancomycin and Ceftazidime was given after 72 hours.

\section{Outcome and Follow-Up}

After 7 days, the symptoms improved with vision of $4 / 60$ and there were no exudates in vitreous. On next follow up after 2 weeks the vision was 5/60 with corneal suture intact. After 2 months there was cataract developed which was operated with suture removal. One month post-operative best corrected vision was $6 / 18$.

\section{Discussion}

Endophthalmitis due to infection after open globe injuries is not uncommon. The incidence of endophthalmitis varies from $3 \%$ to $48 \%$ in various studies after open globe injury depending on a variety of factors which include setting of trauma, delay of repair, retained intraocular foreign body, and involvement of the crystalline lens [1]. The type of pathogenic microorganism, nature of the injury, the presence of a foreign body, and the geographical region in which the trauma occurred are all important factors influencing both treatment and prognosis [2]. There is not a confirmed treatment protocol recommended by the Endophthalmitis-Vitrectomy Study Group [3] in traumatic cases unlike postoperative endophthalmitis. The injury with fire cracker usually results in more of burn injury but in this case there was perforation due to impact of high speed particle from blast of a fire cracker. Usually the high speed particle from firecracker enters into the eye are sterile due to high temperature of it. But in this case, due to the globe remained open for long period without closure there was entry of organism, B. cereus and superadded infection occurred. Bacillus spp. is most common organism isolate after post trauma endophthalmitis [4] although another study showed gram-positive cocci the most frequently identified causative organism, followed by Bacillus species in their study [5]. Urgent intervention with intravitreal injection of broad spectrum antibiotic in our patient lead to resolution of endophthalmitis. As Bacillus spp. is poorly susceptible to Ceftazidime, [4] we repeated the intravitreal injection Vancomycin, [6] only in this patient after 72 hours which showed positive response in form of resolution of infection.

Injury to eye can any time especially to children but there is always an increased incidence of injury during an Indian festival "Diwali" every year where people celebrate it with lights and firecrackers. Due to proper care not taken by parents, children always fall into firecracker injury to eye in form of burn injury or perforation injury which should be noticed by government, policy makers, media and social organization.

\section{Learning Points/Take Home Messages}

a) Proper precaution should be taken to avoid fire cracker injury in eye and health education regarding prevention of fire cracker injury should be given.

b) Earlier referral to Ophthalmologist in case of eye injury can save the patient's sight.

c) Vitreous aspirate and anterior chamber exudates should be sent for microbiological examination before antibiotics started.

\section{References}

1. Zhang $\mathrm{Y}$, Zhang MN, Jiang CH, Yao Y, Zhang K (2010) Endophthalmitis following open globe injury. Br J Ophthalmol 94(1): 111-114.

2. Gokce G, Sobaci G, Ozgonul C (2015) Post-Traumatic Endophthalmitis: A Mini-Review. Semin Ophthalmol 21: 1-5.

3. Endophthalmitis Vitrectomy Study Group (1995) Results of the Endophthalmitis Vitrectomy Study. A randomized trial of immediate vitrectomy and of intravenous antibiotics for the treatment of postoperative bacterial endophthalmitis. Arch Ophthalmol 113(12): $1479-1496$

4. Jindal A, Pathengay A, Mithal K, Jalali S, Mathai A, et al. (2014) Endophthalmitis after open globe injuries: changes in microbiological spectrum and isolate susceptibility patterns over 14 years. J Ophthalmic Inflamm Infect 4(1): 5.

5. Long C, Liu B, Xu C, Jing Y, Yuan Z, et al. (2014) Causative organisms of post-traumatic endophthalmitis: a 20-year retrospective study. BMC Ophthalmol 14: 34.

6. Sharma S, Padhi TR, Basu S, Kar S, Roy A, et al. (2014) Endophthalmitis patients seen in a tertiary eye care centre in Odisha: a clinicomicrobiological analysis. Indian J Med Res 139(1): 91-98. 
This work is licensed under Creative Commons Attribution 4.0 License DOI: 10.19080/JOJO.2018.07.555702

Your next submission with Juniper Publishers
will reach you the below assets
- Quality Editorial service
- Swift Peer Review
- Reprints availability
- E-prints Service
- Manuscript Podcast for convenient understanding
- Global attainment for your research
- Manuscript accessibility in different formats
( Pdf, E-pub, Full Text, Audio)
- Unceasing customer service
Track the below URL for one-step submission
https://juniperpublishers.com/online-submission.php

